Vietnam Journal of Mechanics, VAST, Vol.29, No. 4 (2007), pp. 517-528

\title{
RESEARCH ON AERODYNAMICS OF A WING-IN-SURFACE-EFFECT SHIP BY THEORY AND EXPERIMENT
}

\author{
Phan Xuan Tang, Ngo Tri Thang \\ Technological Air Force and Air Defense Institute \\ PHAM VU UY \\ Military Center of Science and Technology \\ DUONG NGOC HAI \\ Institute of Mechanics, Vietnamese Academy of Science and Technology
}

\begin{abstract}
The paper presents the results of theoretical and experimental studies of the aerodynamic characteristics of a wing-in-surface-effect ship (WISES), which was made under coordination of the Institute of Mechanics, Vietnamese Academy of Science and Technology. The theoretical researches are carried out by the half analytical method and together by the linear and nonlinear vortex lattice methods. The experiment was conducted by the model on wind tunnel OT1 of The Technical Institute of Air Force Air Defense.
\end{abstract}

\section{INTRODUCTION}

One of the most important problems in early manufacturing process is to design hydroaerodynamic diagram, to determine aero characteristic, stability and control of craft. These aero characteristics are, on one hand, to determine the perfect of the diagram and, on the other hand, to survey the stability, control, loading and structure's durability of craft. Methods were used to determine aero characteristics of airplane are numerous, such as theoretical calculation, testing model in wind tunnel and testing flight. Generally, in modeling process of aero plane, theoretical calculation and testing model are inevitable. Based on hydro-aerodynamic diagram, we have done many theoretical calculations by numerous methods and have tested wing-in-surface-effect ship (WISES) in wind tunnel OT1. The results are shown in this article.

\section{THEORETICAL RESEARCH}

\subsection{Half experiment method}

Half experiment method is one of the simplest methods to calculate wero-characteristic of airplane. References $[5,12]$ showed all necessary equations to calculate aero-characteristic. The following equation [5] will show how to calculate lift coefficient and drag coefficient with ground effect and constant angle of attack $\alpha$ : 


$$
\begin{aligned}
& \frac{C_{y}}{C_{y \infty}}=1+\sigma-\frac{\sigma \lambda \cos \chi_{0.5}}{2 \cos \chi_{0.5}+\sqrt{\lambda^{2}+\left(2 \cos \chi_{0.5}\right)^{2}}}-\frac{\beta}{\frac{4 \pi h}{b_{c p}}}\left(c_{y \infty}-\frac{C_{y}^{\alpha}}{\frac{16 h}{b_{c p}}}\right), \\
& \beta=\sqrt{1+\left(\frac{2 h_{\phi}}{l}\right)^{2}}-\frac{2 h_{\phi}}{l}, \\
& \sigma=\exp \left[-2.48\left(\frac{2 h_{\phi}}{l}\right)^{0.768}\right], \\
& 2 h_{\phi}=h+h_{\phi k}, \\
& c_{x \infty}=c_{x o}+c_{x i \infty}, \\
& c_{x i \infty}=\frac{1+\delta}{\pi \lambda} c_{y \infty}^{2} \\
& c_{x}=c_{x o}+c_{x i}, \quad 0 \leq \delta \leq 0.11, \\
& c_{x i}=\frac{1-\sigma}{1-\frac{\beta c_{y}}{4 \pi h / b_{c p}}} c_{x i \infty},
\end{aligned}
$$

where $b_{c p}=S / l ; h$ : distance from aerodynamic center to restricted surface; $h_{\phi k}$ : distance from behind corner of aero plane to restricted surface; $S$ : wing's area; $l$ : wing's span; $c_{y \infty}$, $c_{x \infty}$ : lift and drag coefficient of aero plane without effect of restricted surface; $c_{y}, c_{x}$ : lift and drag coefficient of aero plane with effect of restricted surface; $\chi_{0.5}$ : arrow angle at position 0.5 of mean aero chord; $\lambda$ : Aspect ratio of wing; $c_{x o}$ : Skin friction and form drag coefficient; $c_{x i}$ : induced drag coefficient.

\subsection{Linear and nonlinear vortex lattice method (VLM)}

In this method, the continuous distributions of flow parameters are modeled by partial perspective approach. That means the continuous vortex layer and free vortex system will be modeled by VLM and the continuous variation of boundary conations are modeled approximately by step change. Thus, at each time of calculation such as $\tau=0, \tau_{1}, \tau_{2}$, $\tau_{3}, \ldots \tau_{r}$, boundary conditions, vortex intensity could change dramatically, but within these interval, they remains constantly. Besides, at each time of calculation, vortex leaves the free vortex system and replaces lifting surface of aero plane. In many cases of flow which surrounds arbitrary object, the continuous Laplace equation is replaced by linear differential equation. Because of the linearity of equation, velocity, which is accumulated by induced velocity from VLM system, is also satisfied equation of condition when velocity is 0 at infinite points with lifting surface and free vortex layer. As a result, the problem is just to determine intensity of VLM at time of calculation and to satisfy conditions on surface of aero plane: closed conditions of vortex system, hypothesis about limited velocity at behind corner of lifting surface, initial conditions (with unsteady problems). All the boundary conditions are satisfied at checked points. Numbers of checked points are limited and arbitrary. 


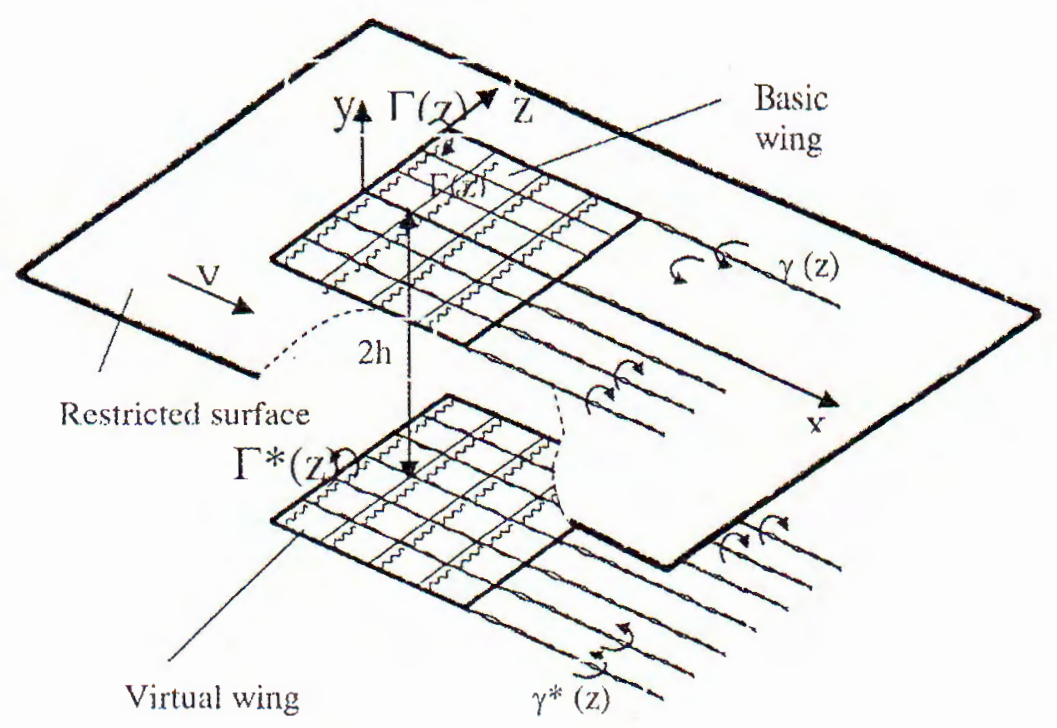

Fig. 1. Calculation model of VLM which is linear with a plane thin wing, which has limited spant and moves near to plane to restricted surface

With this approach, the complex boundaries problems become system of algebraic equation with unknowns are intensity of vortex lattice. The stability of system is good. In nonlinear steady problems, determination of lattice vortex's intensity and structure of free vortex system are done together with the support of iteration method. After each iteration, value of lattice vortex's intensity and its position are corrected. Wit]. linear unsteady problems, lattice vortex's intensity and its position are determined by steps.

Result at the beginning of one interval is result at the end of last interval. After deternining solutions of linear algebraic systen, we use theorem of Giucopskii about "small interval" to determine acro claracteristic of aero plane [4].

Effect of restricted surface with aero characteristic of wing is caleulated by intrcducing virtual wing, which is also modeled by horizontally associated VLM with intensity $\Gamma *(z)$ and absolute value $\Gamma(z)$ but opposite rotation direction. With such model, velocities which are normal to induced restricted surface of basic VLM and virtual VIM eliminate each other and ensure to satisfy non slip boundary condition on restricted surface.

Calculation model with non-plane restricted surfacc by linear VIM is shown in Fig. 2

Lifting surface of wing is replaced by one continuous vortex layer. In calculation, this layer is divided and modeled by VLM fiber along span, to illustrate variation in intensity of vortex fiber along span by dividing vortex fiber into vortex interval with constant intensity (value of intensity of consecutive intervals are different)

These vortex intervals are called horizontally associated rortexes (11on-unit intensity is denoted as $\Gamma$ ). Since cach horizontally associated vortex can not stop at its two ends so the end of each vortex is continued by vortex interval until behind corner of wing. These vortexes are callod vertically associated vortexes. Vertically associated vortexes do not stop at the behind corner of wing but are continued by free vortex which is relcased at the behind corner (is called vortex system I). Since each free vortex is the continuation of vertically associated vortex system which release at the same position, so its intensity 


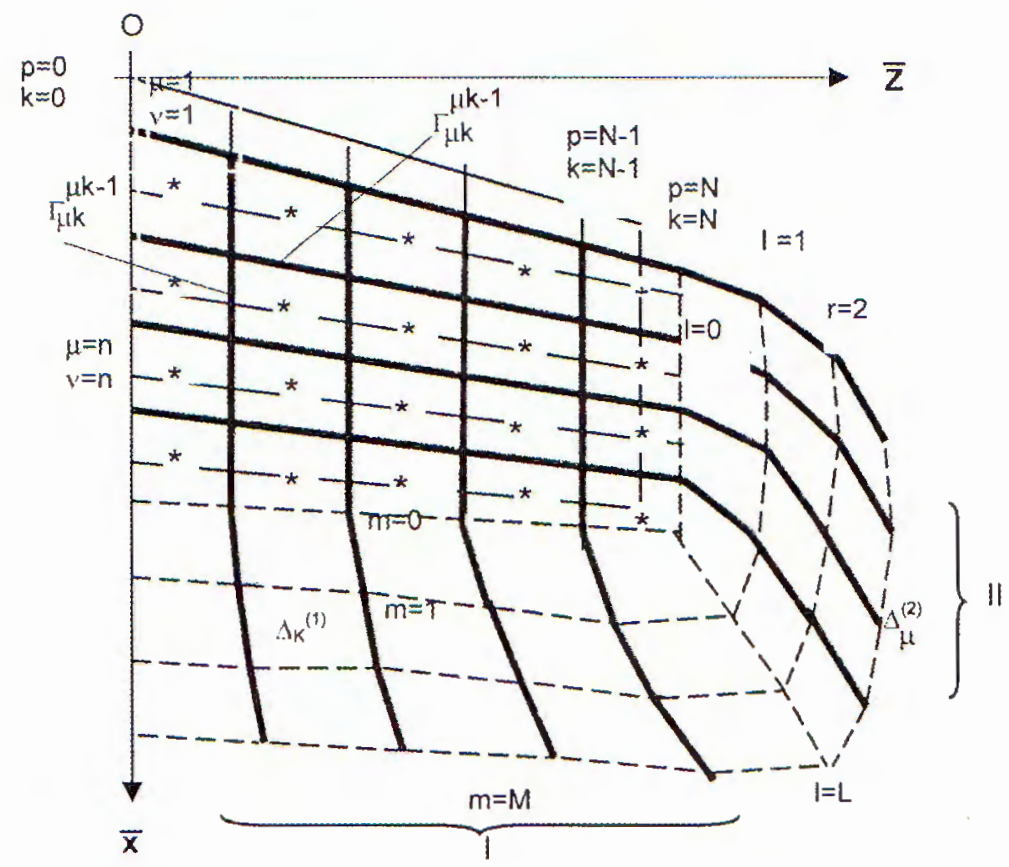

Fig. 2. Model of vortex in trapezium wing with linear stopped problem

is equal to algebraic sum of vortex's intensity release from different position. As a result, intensity of free vortexes are different (non-unit intensity is denoted as $\Delta^{(1)}$ ). When angle of attack $\alpha=0$, vortexes lie in wing's plane. When $\alpha \neq 0$, they form space system. In calculation process, these vortex fibres are divided into continuous vortex interval which has same intensity.

Space direction of these vortex intervals are determined by direction of velocity vector at the beginning of each vortex interval. Similar with vertically associated vortexes, horizontally associated vortexes do not stop at the end of wing but are continued by free vortexes which are released at wing's end. Fiber vortex system does not lie in wing's plane but create space vortex system (which is called vortex system II). In calculation, each vortex fiber of system II is divided into vortex interval which has same intensity (non-unit intensity is denoted as $\Delta^{(2)}$ ) and space direction of each interval is also determined by relative velocity at the beginning of each interval.

Based on model of VLM, we choose position of horizontally associated vortex, which is along checked points so that it is satisfied hypothesis of Traplugin-Giucopskii and determine induced velocity from horizontally, vertically associated vortex and free vortex system I, II at each checked point. Applied boundary condition on each checked point, together with create relation between intensity of horizontally associated vortex and vertically associated one, between associated vortex with free vortex system I, II, and construct algebraic equation system with solutions are intensity of horizontally associated vortex $\Gamma_{\mu k}^{\mu k-1}$ in case no restricted surface [4].

$$
\sum_{k=1}^{N} \sum_{\mu=1}^{n} \Gamma_{\mu k}^{\mu k-1} a_{\mu k v}^{\mu k-1 p p-1}=-2 \pi \sin \alpha
$$


$\nu=1, \quad 2, \quad 3 \ldots \ldots \ldots \ldots . n ; p=1,2,3 \ldots \ldots \ldots . .$.

where $\Gamma_{\mu \kappa}^{\mu \kappa-1}$ - horizontally associated vortex's intensity; $a_{\mu \kappa v}^{\mu \kappa-1 p p-1}$ - function of non unit induced velocity components, which are created by associated vortex system and free vortex system at checked point.

Intensity of horizontally associated vortex and structure of free vortex system I and II are determined concurrently by integration at each value of angle of attack $\alpha$.

At first, we determine values of vortex's intensity $\Gamma_{\mu \kappa}^{\mu \kappa-1}$ when angle of attack approach 0 . In linear calculation model, free vortex system lies in wing's plane and its direction is concurrent with direction of velocity $\mathrm{U}_{0}$. After that, at large value of angle of attack $\alpha$, based on predetermined value of $\Gamma_{\mu \kappa}^{\mu \kappa-1}$, we calculate structure of free vortex system I and II in space, then determine the correct value of $\Gamma_{\mu \kappa}^{\mu \kappa-1}$, and repeat this process until $\Gamma_{\mu \kappa}^{\mu \kappa-1}$ reaches constant value.

Basic linear algebraic equation system, which is used to determine intensity of VLM in restricted surface problem, is:

$$
\sum_{i=1}^{M} \sum_{k=1}^{N} \sum_{\mu=1}^{n} \Gamma_{\mu k i}^{\mu k-1} a_{\mu k \nu i}^{\mu k-1 p p-1}=-2 \pi f_{n}
$$

$\nu=1, \quad 2, \quad 3 \ldots \ldots \ldots \ldots n ; \mathrm{p}=1,2,3 \ldots \ldots \ldots \mathrm{N}$.

where $m$ - numbers of plane to illustrate aero plane's wing and restricted surface; $f_{n}$ function of non-unit displacement at checked points on aero plane's wing and restricted surface.

For VLM nonlinear:

$$
\left\{\begin{array}{l}
a_{\mu N \nu i}^{\mu N-1 p p-1}=v_{\sigma \bar{n} \mu N 0 \nu i}^{\mu N-1 p p-1}+v_{\sigma \bar{n} \mu N-10 \nu i}^{n+1 N-1 p p-1}-\sum_{m=1}^{M} v_{\sigma \bar{n} m N-10 \nu i}^{m+1 N-1 p p-1}+\sum_{l=1}^{L} v_{\sigma \bar{n} \mu l 0 \nu i}^{\mu l+1 p p-1} k=N \\
a_{\mu k \nu i}^{\mu k-1 p p-1}=v_{\sigma \bar{n} \mu k 0 \nu i}^{\mu k-1 p p-1}+v_{\sigma \bar{n} \mu k-10 \nu i}^{n+1 k-1 p p-1}-v_{\sigma \bar{n} \mu k 0 \nu i}^{n+1 k p p-1}-\sum_{m=1}^{M}\left(v_{\sigma \bar{n} y m k-10 \nu i}^{m+1 k-1 p p-1}-v_{\sigma \bar{n} m k 0 \nu i}^{m+1 k p p-1}\right) \\
\text { with } k<N-1 ; \quad 1 \leq i \leq M ;
\end{array}\right.
$$

And for VLM linear:

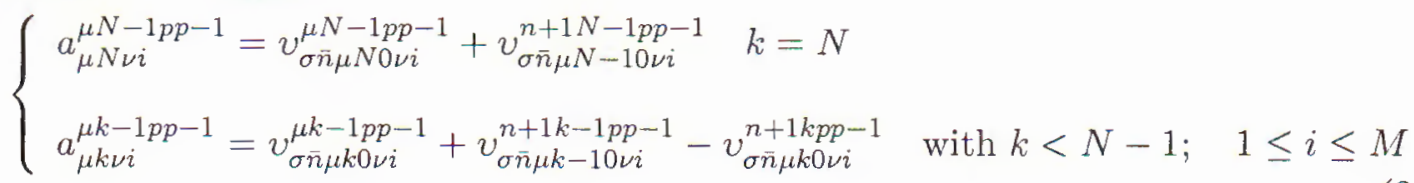

$v_{\sigma \bar{n}}$ is velocity's component which is normal to lifting surface and restricted surface.

To determine velocity component $v_{\sigma \bar{n}}$, we use angle which is made by velocity vector with normal vector of aero plane's surface, restricted surface at checked point $\xi$ :

$$
v_{\sigma \bar{n} \mu k 0 \nu i}^{\mu k-1 p p-1}=v_{\sigma \bar{n} \mu k 0 \nu i}^{\mu k-1 p p-1} \cos \xi \text {. }
$$

Notice, that

Linear model proposes that the vortex lines are lines nonlinear mode of VLM take account the nonlinearity of the vortex line. In this case the vortex line may have complex spatial structure.

Solve system (2.3) and use equation in (2.7), (2.8) to determine loading and aerodynamics coefficient of WISES. 
Lift coefficient:

$C_{y}=\sum_{m=1}^{M}\left\{\frac{2}{n_{m}} \frac{b_{m}^{2}}{S_{m}} \sum_{p}^{N_{m}} \sum_{\varepsilon=1}^{n_{m}}\left[\begin{array}{l}\Delta \bar{p}_{m \varepsilon p}^{\varepsilon p-1} \bar{b}_{m p p-1} \bar{l}_{m p p-1}+ \\ \frac{1}{2}\left(\Delta \bar{p}_{m \varepsilon p}^{\varepsilon+1 p} \bar{b}_{m p} \Delta \bar{l}^{(p)}+\Delta \bar{p}_{m \varepsilon p}^{\varepsilon+1 p} \bar{b}_{m p-1} \Delta \bar{l}^{(m p-1)}\right)\end{array}\right]\right\}$.

Pitching moment:

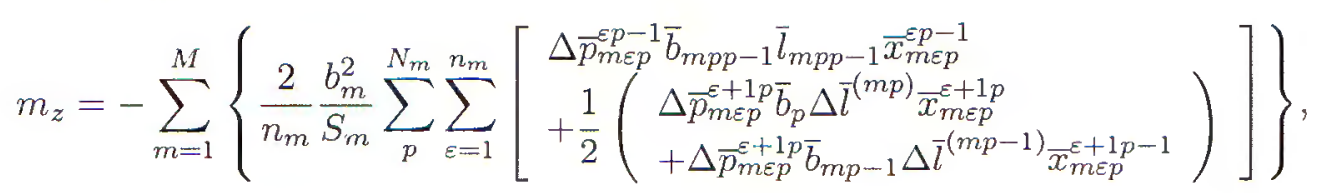

where

$$
\begin{aligned}
& \Delta \bar{p}_{\varepsilon p}^{\varepsilon p-1}=2 w_{0 \varepsilon p}^{\varepsilon p-1} \cdot \gamma_{\varepsilon p}^{\varepsilon p-1} ; \quad \varepsilon=1,2, \ldots, n_{m}, \quad p=1,2, \ldots, N_{m} ; \quad m=1,2, \ldots, M, \\
& \Delta \bar{p}_{\varepsilon p}^{\varepsilon+1 p}=2 . w_{0 \varepsilon p}^{\varepsilon+1 p} \cdot \gamma_{\varepsilon p}^{\varepsilon+1 p} ; \varepsilon=1,2, \ldots, n_{m} ; \quad p=1,2, \ldots, N_{m}-1 ; m=1,2, \ldots, M, \\
& \gamma_{m \varepsilon p}^{\varepsilon p-1}=\frac{\Gamma_{m \varepsilon p}^{\varepsilon p-1}}{\bar{b}_{m p p-1}} \cdot \frac{n_{m}}{\cos \chi_{m \varepsilon p}^{\varepsilon p-1}} ; \varepsilon=1,2, \ldots, n_{m}, ; \quad p=1,2, \ldots, N_{m}, \\
& \gamma_{m \varepsilon p}^{\varepsilon+1 p}=\frac{\Gamma_{m \varepsilon p}^{\varepsilon+1 p}}{\Delta \bar{l}^{(m p)}} ; \varepsilon=1,2, \ldots, n_{m} ; p=1,2, \ldots, N_{m}-1, \\
& \Delta \bar{l}^{(m p)}=\frac{1}{2}\left(\vec{l}_{m p+1 p}+\bar{l}_{m p p-1}\right), \bar{l}_{p p-1}=\bar{z}_{0 p-1}-\bar{z}_{0 p} .
\end{aligned}
$$

In which: $\gamma_{\varepsilon p}^{\varepsilon p-1}$ and $\gamma_{\varepsilon p}^{\varepsilon+1 p}$ are non-dimension vertical and horizontal whirl intensity of vortex layer; $w_{0 \varepsilon p}^{\varepsilon-1}$ and $w_{0 \varepsilon p}^{\varepsilon+1 p}$ are non-dimension velocity on mid-point of vertical and horizontal whirl; $\chi_{m \varepsilon p}^{\varepsilon p-1}$ is arrow-shaped angle between points $\varepsilon p$ and $\varepsilon p-1$

\section{EXPERIMENT}

\subsection{Design, manufacture of model WISES and restricted surface}

Model of WISES and restricted surface affect to the correctness of experiment in wind tunnel. Designed model of WISES is based on hydro-aero diagram and is satisfied similar standard of geometry and kinetics with object and surrounding flow [6 - 8]. Besides, the model must be satisfied "no obstructed flow" condition in test tunnel and ability of measurement facilities. Model of WISES is designed to be similar with real object of scale 1: 6.20. Dimension of components such as body, main wing, front transfer tail (elevator), main wing with end-plate and dimension between components are based on detail drawing and nodel. Model of craft is manufactured by composite material. Components of model are manufactured. In the process of manufacture, components are checked in order to satisfy dimension, stability diagram and symmetric of model. All surface of model are made to be smooth.

Restricted surface is designed to be plane and can be change in altitude during experiment. Dimension of restricted surface is based on results of effects of restricted surface to aero characteristic of aero plane with low altitude [1 - 2]. Restricted surface has dimension 2400-2400 mm, and is made by glued wood with thickness of $10 \mathrm{~mm}$, fixed plainly on stable steel paddle. 


\subsection{Experiment of WISES in wind tunnel OT1}

\subsubsection{Apparatus}

Apparatus contains wind tunnel OT1, wind tunnel balance with the six components of force and moment and facilities to determine flow's velocity in tunnel.

\subsubsection{Methods to test WISES}

Test of WISES is processed by following methods:

- Test of different model which has small elongation coefficient $\lambda_{c}$

a) In case of free surrounding flow $\bar{h}=\infty$ (Relative altitude $\bar{h}=h / b_{c p} ; h$ is distance from behind corner to restricted surface, $b_{c p}$ wing's chord)

b) In case $\bar{h} \neq \infty$.

- Test of model of WISES in case free surrounding $\bar{h}=\infty$ when:

a) Angle of attack $\alpha \neq 0$ and slide angle $\beta=0$;

b) Angle of attack $\alpha=0$ and slide angle $\beta \neq 0$;

c) Both $\alpha \neq 0$ v $\mu \quad \beta \neq 0$.

- Test of WISES model in case of near restricted surface $\bar{h} \neq \infty$ when: angle of attack $\alpha \neq 0$ and slide angle $\beta=0$; angle of attack $\alpha=0$ and slide angle $\beta \neq 0$ and both $\alpha \neq 0$ and $\beta \neq 0$.

\subsubsection{Experiment condition and fundamental data of WISES model}

- Data about force, aerodynamic moment on model and flow's velocity in wind tunnel are calculated in condition of pressure, temperature, moisture at tested time in Technological Air Force and Air Defense Institute.

- Ordinate system of wind tunnel balance is OZY system, in which OXZ concurrent with symmetric plane of model. OX axis has the same line but opposite direction with wind velocity, $\mathrm{OZ}$ axis is perpendicular with $\mathrm{OX}$ axis, point down, and $\mathrm{OY}$ axis is perpendicular with OXZ plane, point to right with wind velocity.

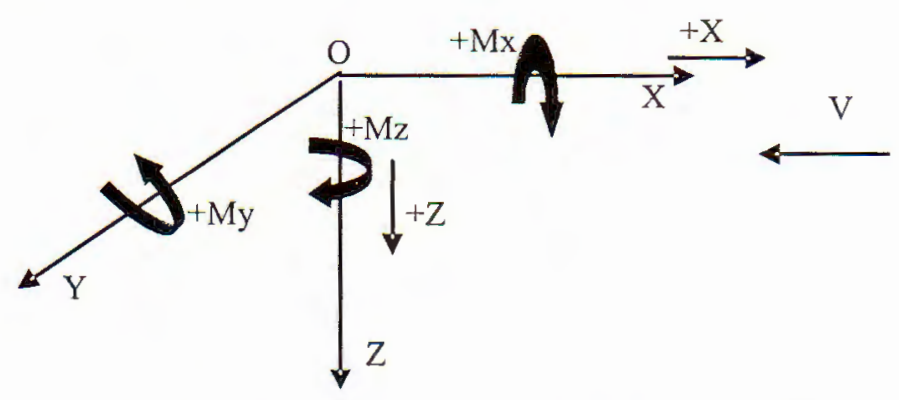

Fig. 3. Sign convention of forces and moments

However, because of the convenience and to unite sign convention in documents of aerodynamic of common aero plane, sign conventions in $\mathrm{OZ}$ axis are replaced by $\mathrm{OY}$ axis, and sign convention in $\mathrm{OY}$ axis are replaced by $\mathrm{OZ}$ axis.

- Because of fixed frame, model has mechanism to change angle $\alpha$ and $\beta$ in experiment, so fixed model's point with wind tunnel balance can not lies in longitudinal axis of model (fixed frame lies outside model).

Fundamental data of WISES model: Wing's area $S_{c}: 0.296 \mathrm{~m}^{2}$; Span's chord length $b_{c}: 0.37 \mathrm{~m}$; Span length $l_{c}: 0.800 \mathrm{~m}$; Distance from fixed model's point to wing's front 
corner $X_{T}: 0.021 \mathrm{~m}$. Dimension and experiment's picture in wind tunnel OT1 are shown in Fig. 4.
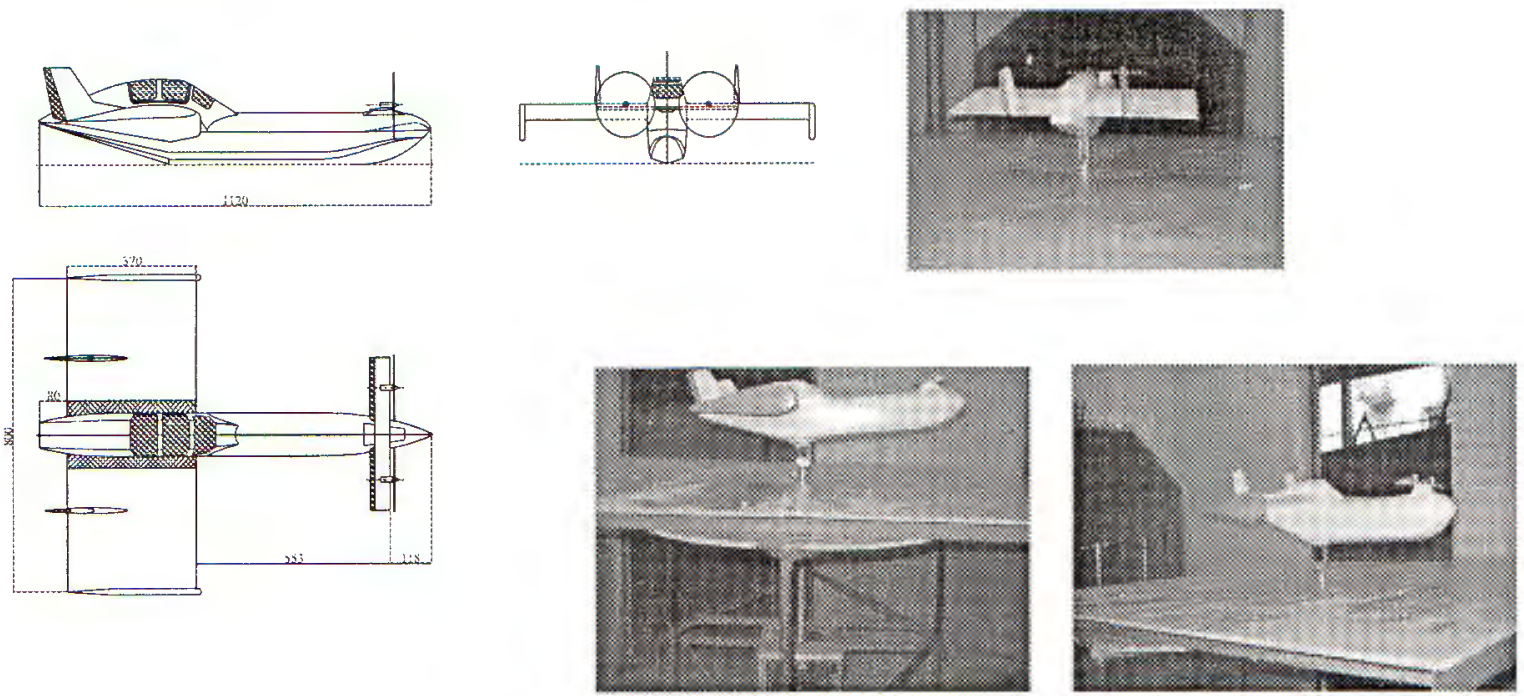

Fig. 4. Dimension and experiment's picture in wind tunnel OT1

\section{EXPERIMENTAL RESULTS AND THEORETICAL CALCULATIONS AERO CHARACTERISTIC OF WISES}

\subsection{Model is used to calculate aero characteristic}

+ Computational method: nonlinear steady VLM.

- Build calculation program which is based on checked model.

- Small velocity interval; with effect of surface; Wing canard: $5 \times 6$ ( 5 spans, each span have 6 vortexes); behind wing: $10 \times 9$. Numbers of free vortex 25 .

+ Similar model:

- Take into account effect of two wings: canard and behind wing are factors create lifting force and control longitudinal channel. Neglect effect of body on lifting.

Two wings remain geometric components, with space arrangement likes in aero plane.

- Camber of lifting surface is ordinate of average line: with canard: accord to profile NACA 0012. Lifting wing accord to profile NACA 3409 with chord which has 85 percent is bended about $5^{O}$ (profile with shape $S$ ). Main wing angle create $3^{O}$ with longitudinal axis.

Control effect: control wing occupy $1 / 4$ chord and all corner. Neglect the effect of propeller.

+ Calculation is made in condition: $M=\frac{V}{a}<0.5$ ( $M$ : mach number, $V$ : aircraft velocity, a: speed of sound). Distance from assumed center of gravity to head $4.30 \mathrm{~m}$; Characteristic length of chord is $2.3 \mathrm{~m}$; Characteristic area of wing is $10.12 \mathrm{~m}^{2}$

\subsection{Calculation results and testing model}

Aero characteristic of WISES are represented by coefficient of force and aerodynamic moment as well as relationship between these coefficients and kinetics parameter of wing 
and craft. Here, we research mainly on coefficient of force and aerodynamic moment such as $c_{y}, c_{x}, m_{z}$ and kinetic paramciers such as $\alpha, \beta$, relative altitude $\bar{h}=\mathrm{h} / \mathrm{b}_{c p}$ ( $h$ is distance from behind corner to restricted surface, $b_{c p}$ wing's chord).

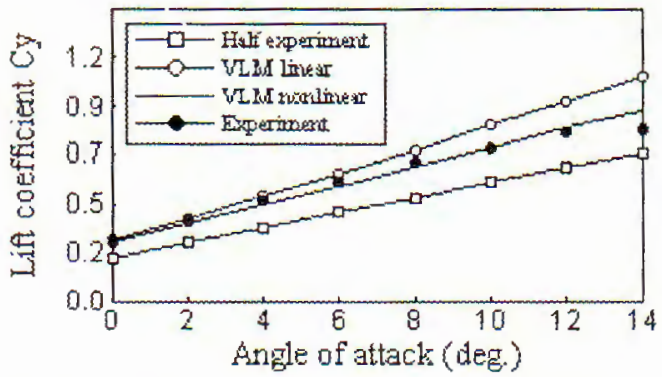

Fig. 5.1. Dependence of lift coefficient $c_{y}$ on angle of attack $\alpha$ (without restricted surface)

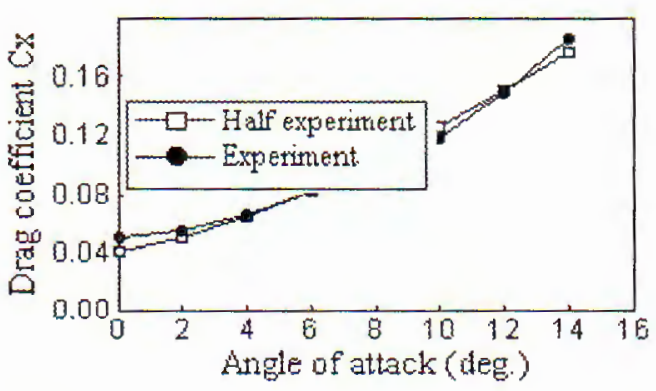

Fig. 5.2. Dependence of drag coefficient $c_{x}$ on angle of attack $\alpha$ (without restricted surface)

Results from calculation and experiment are shown in Fig. $5.1 \div 5.14$.

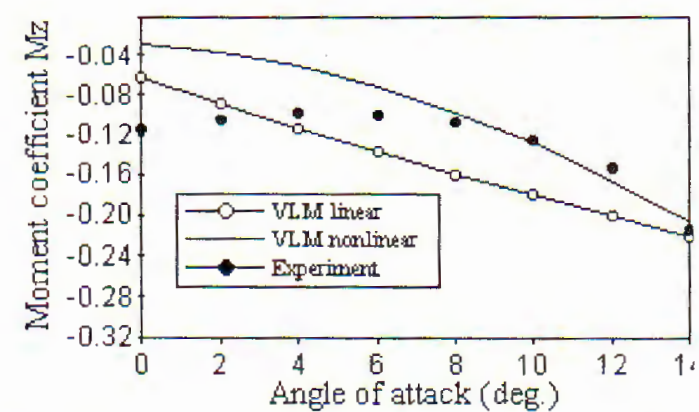

Fig. 5.3. Dependence of pitching moment $m_{z}$ on angle of attack $\alpha$ (without restricted surface)

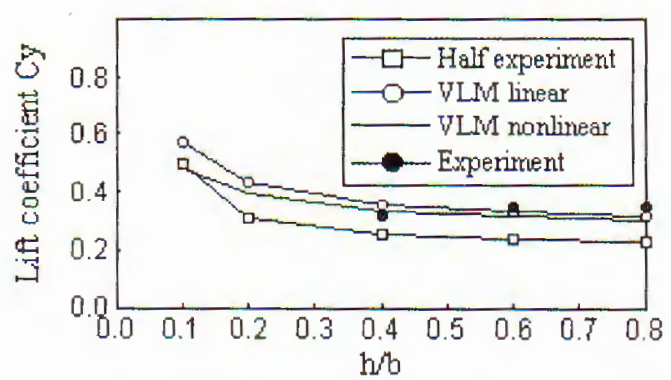

Fig. 5.5. Dependence of lift coefficient $c_{y}$ on altitude $\bar{h}$ at angle of attack $\alpha=0^{\circ}$

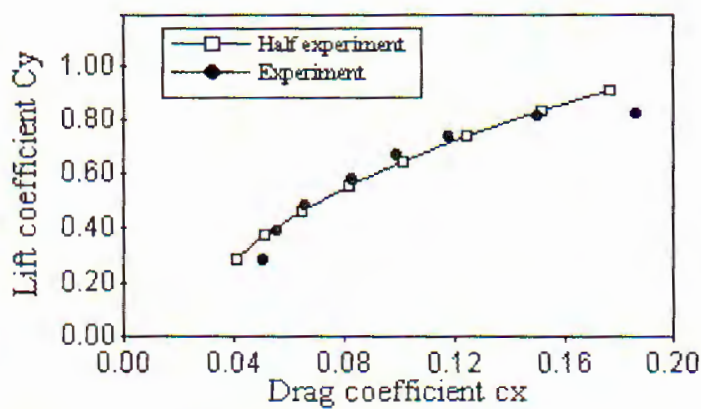

Fig. 5.4. Polar diagram of wing-in-surfaceeffect ship (without restricted surface).

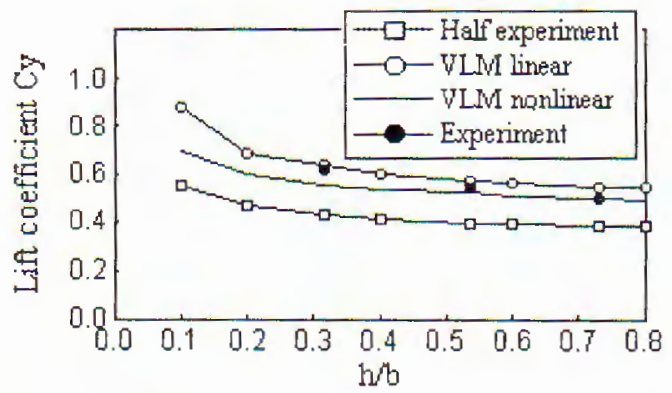

Fig. 5.6. Dependence of lift coefficient $c_{y}$ on altitude $\bar{h}$ at angle of attack 


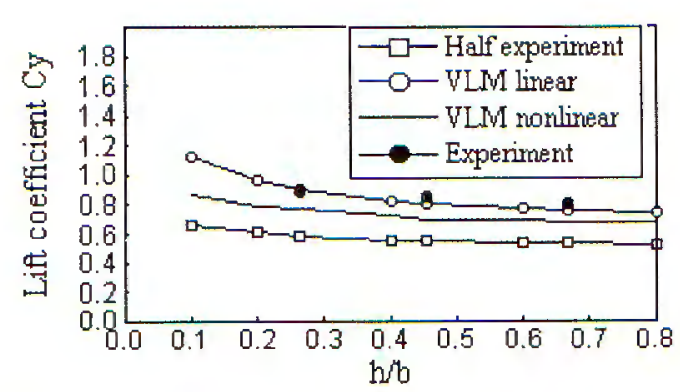

Fig. 5.7: Dependence of lift coefficient $c_{y}$ on altitude $\bar{h}$ at angle of attack $\alpha=8^{\circ}$

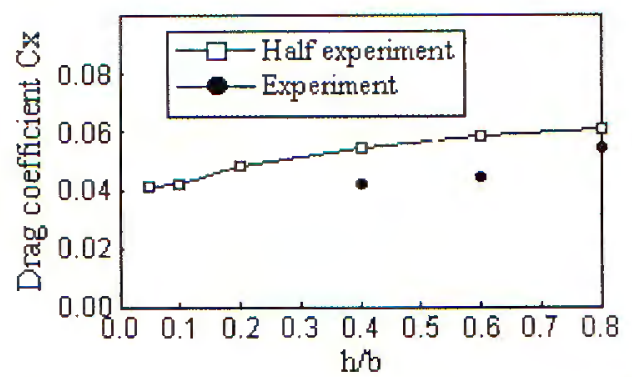

Fig. 5.9: Dependence of drag coefficient $c_{x}$ on altitude $\bar{h}$ at angle of attack $\alpha=0^{\circ}$

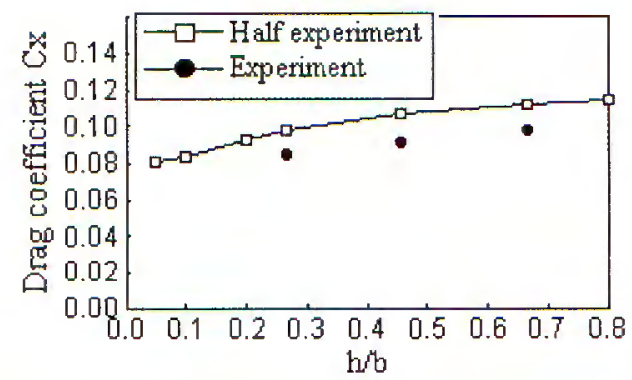

Fig. 5.11. Dependence of drag coefficient $c_{x}$ on altitude $\bar{h}$ at angle of attack $\alpha=8^{\circ}$

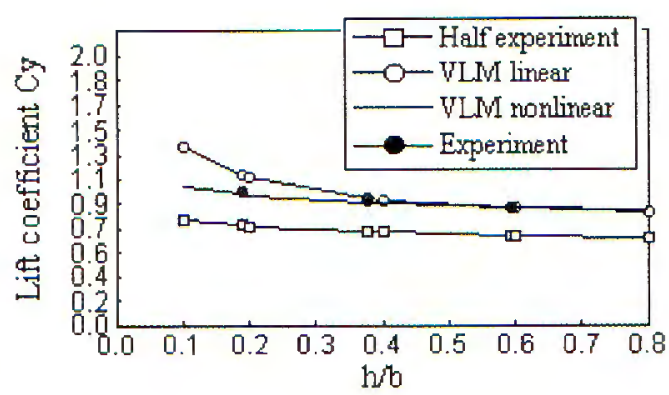

Fig. 5.8. Dependence of lift coefficient $c_{y}$ on altitude $\bar{h}$ at angle of attack $\alpha=12^{\circ}$

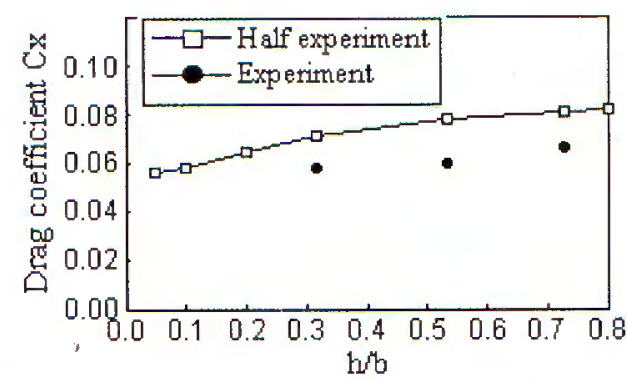

Fig. 5.10. Dependence of drag coefficient $c_{x}$ on altitude $\bar{h}$ at angle of attack $\alpha=4^{o}$

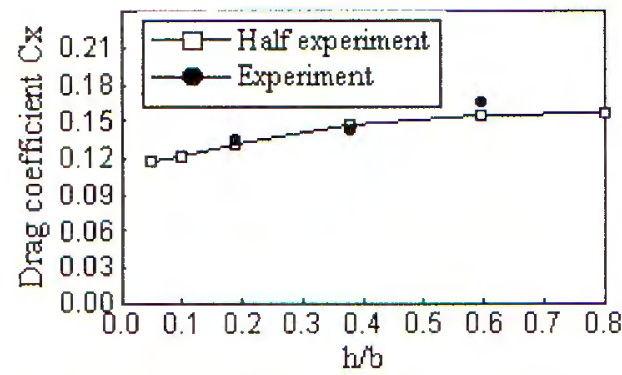

Fig. 5.12. Dependence of lift coefficient $c_{y}$ on altitude $\bar{h}$ at angle of attack $\alpha=12^{\circ}$

\section{DISCUSSION}

Fig. $5.1-5.3$ show results of lift coefficient $c_{y}$, drag coefficient $c_{x}$ and moment $m_{z}$ of WISES in case of free surround flow (neglect effect of restricted surface). Obviously, these results are consent with all articles which are published before ([1 - 3], [10]) with similar aero plane.

Fig. 5.5 - 5.8 show relationship between lift coefficient $c_{y}$ of craft and relative altitude $\bar{h}$. We can see that with different calculation method (linear, nonlinear VLM, halt experiment, experiment), qualitative results are similar. Furthermore, these results increase gradually when relative altitude $\bar{h}$ decrease, lift coefficient $c_{y}$ of craft at relative altitude 


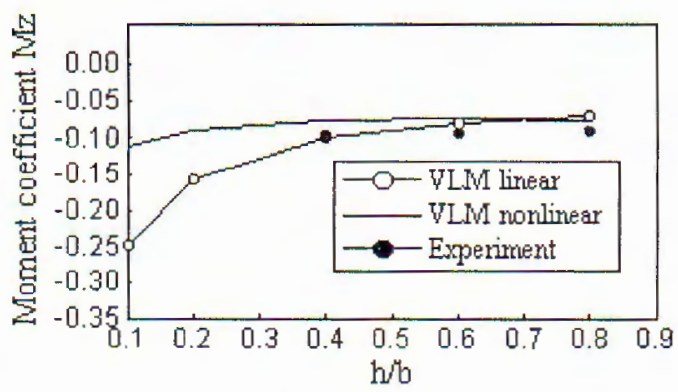

Fig. 5.13. Dependence of pitching moment coefficient $m_{z}$ on relative $\bar{h}$ at angle of attack $\alpha=0^{\circ}$

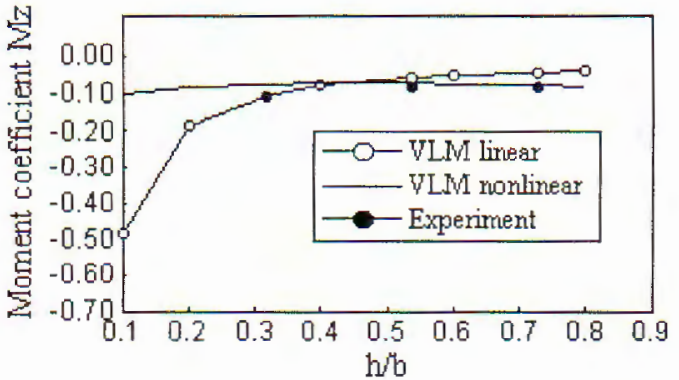

Fig. 5.14. Dependence of pitching moment coefficient $m_{z}$ on relative $\bar{h}$ at angle of attack $\alpha=4^{\circ}$

$\bar{h}=0.1$ has average value of 1.5 times of $c_{y}$ at $\bar{h}=0.8$. These results are consent with [10, 11].

Fig. 5.9 - 5.12 show relationships between drag coefficient $c_{x}$ and relative altitude $\bar{h}$ of craft in half experiment and experiment at angle of attack $\alpha=0,4,8$ and $12^{\circ}$. Calculate by half experiment use (2.1) with $c_{x o}=0.026$. We can see that both methods are appropriate, the difference is not large and can be accepted.

Fig. 5.13 - 5.14 show relationships between coefficient of pitching moment $m_{z}$ with relative altitude $\bar{h}$ at angle of attack $\alpha=0,4^{\circ}$ at calculation point with nonlinear VLM and at fixed point with experiment at leading edge $X_{T}=0.021 \mathrm{~m}$. Values are accepted and agreed with published articles [9-11].

\section{CONCLUSION}

From the research results and discussion, we have following conclusions:

1. Qualitative and quantitative aero characteristics of WISES at free surround flow and near restricted surface are consent with reality and variation law of kinetic parameters such as $\alpha, \beta$ and $\bar{h}$.

2. Experiment are consent with theoretical methods. Especially, nonlinear VLM are the closest method with experiment. That means nonlinear VLM are correct and stable.

With all values of coefficient of force and aerodynamic moment which are contained from experiment in wind tunnel OT1 and theoretical calculation, we observe:

- Lift coefficient $c_{y}$ at angle of attacks ensure craft to be maintain. However, in takeoff we must take into account effect of two propellers of engine which is neglected in this article.

- Drag coefficient $c_{x}$ of craft at low altitude (near restricted surface) has average value of $c_{x}=0.05$ to 0.08 . If craft flying with velocity $V=150$ to $160 \mathrm{~km} / \mathrm{h}$, power of engine must be larger than $40 \mathrm{ml}$.

- Value of moment pitching $m_{z}$ and ordinal of pressure center $\bar{X}_{a}$ ensure craft to be stable in longitudinal direction, when center of gravity $\bar{X}_{T}=0.19$ (calculated from behind wing's chord).

Acknowledgement. The publication is partly financed by National Basic Research Program 


\section{REFERENCES}

1. Dương Ngọc Hải, Phạm Vũ Uy, Phan Xuân Tăng, Research on effect of restricted surface to aerocharacteristic of aeroplane, Proc. of Scientific Conference on the $25^{\text {th }}$ Anniversary of Mechanical Institute, Hanoi, Vietnam 2004.

2. Duong Ngoc Hai, Phan Xuan Tang, Ngo Tri Thang, Pham Vu Uy, Study of Wing-in-Surface Aerodynamic Characteristics by Experiment and Discrete Vortex Method, The $3^{\text {rd }}$ AsiaPacific Workshop on Marine Hydrodynamics APHydro-2006, Shanghai, China, June 27-28, 2006. pp.39-44.

3. Design and calculation aerodynamic property of VNS-41 aeroplane, Factory A41, Vietnam 2005

4. S. M. Б елосерковский, Отрывное и безотрывное обтекание тонких крыльев идеальной жидкостю, Изд. "Наука", Москва 1978.

5. Г. А. Колесников, Аэродинамика летательных аппаратов, Изд. "Машиностроение", Москва 1993.

6. Л. И. Седов, Методы подобия и размерности в механике. Изд. "Наука", Москва 1977.

7. Мартынов, Экспериментальная аэродинамика. Изд. "Оборонгиз", Москва 1952.

8. Е. Л. Бедржиский, Б. С. Дубов, А. Н. Радциг, Теория и практика аэродинамического эксперимента, Изд. МАИ, Москва, 1990.

9. Bruford David, Wing in ground effect, Private Pilot USA, 1998.

10. Iwashita, Watanabe, Numerical and experimental studies on aerodynamic properties of a canard-Configuration WIG flying over the still water and waves, Busan, Korea. June 21-22. 2004.

11. Hiromichi Akimoto, Syozo Kubo and Motoki Tanaka, Investigation of the Canard Type WingIn-Surface-Effect-Ship, FAST 2003 Ischia (Italy).

12. З. Торенбик, Проектирование дозвуковю самолетов, M. axinostroenie, Mockva 1983.

Received June 21, 2007

\section{NGHIÊN CỨU LÝ THUYẾT VÀ THỰC NGHIẸM DẶC TÍNH KHÍ DộNG CƯA TÀU DỆM KHÍ}

Bài báo trình bày các kết quá nghiên cứu lý thuyết và thực nghiệm về đặc tính khí dộng của tàu đệm khí do Viện Cơ học, Viện Khoa học Công nghệ Việt nam đang điều phối chuân bị chế tạo, thử nghiệm. Nghiên cứu lý thuyết được thực hiện trên cơ sớ phương pháp bán giải tích, cùng với tính toán số bằng phương pháp xoáy rời rạc tuyến tính và phi tuyến. Nghiên cứu thực nghiệm được tiến hành trên mô hình trong ống khí động OT1 của Viện Kỹ thuật Phòng không - Không quân. 